Nova Southeastern University

Florida

NSUWorks

Biology Faculty Articles

Department of Biological Sciences

8-8-2021

\title{
Effects of COVID-19 on Global Research in STEM
}

Michelle Hoang

Nova Southeastern University

Santanu De

Nova Southeastern University, sde@nova.edu

Follow this and additional works at: https://nsuworks.nova.edu/cnso_bio_facarticles

Part of the Biology Commons

\section{NSUWorks Citation}

Hoang, Michelle and Santanu De. 2021. "Effects of COVID-19 on Global Research in STEM." AIJR Preprints , (). doi:10.21467/preprints.331.

This Article is brought to you for free and open access by the Department of Biological Sciences at NSUWorks. It has been accepted for inclusion in Biology Faculty Articles by an authorized administrator of NSUWorks. For more information, please contact nsuworks@nova.edu. 


\title{
AlJR Preprints
}

Section: Coronavirus

Article Id: 331, Version: 1, 2021

DOI: https://doi.org/10.21467/preprints.331

URL: https://preprints.aijr.org/index.php/ap/preprint/view/331

\{Click on above link or DOI to see the latest available version of this article\}

Version 1: Received: 26 July 2021 / Approved: 28 July 2021 / Online: 08 August 2021

\section{Effects of COVID-19 on Global Research in STEM}

\author{
Michelle Hoang and Santanu De* \\ Department of Biological Sciences, Halmos College of Arts and Sciences, Nova Southeastern University, \\ Fort Lauderdale, Florida, USA
}

${ }^{*}$ Corresponding author

\begin{abstract}
A global public health emergency like the Coronavirus Infectious Disease 2019 (COVID-19) pandemic requires accurate and timely data collection in the research community. High impact research in science, technology, engineering, and mathematics (STEM) has been prioritized in the fight against COVID19. The present study investigated the impact of COVID-19 on STEM research and the collaboration between global research institutions and industries. It was noted that COVID-19 had caused significant delays in non-COVID-19-related research projects and the onset of several remote studies. Most importantly, researchers in the STEM fields directed their attention and expertise to help mitigate virus transmission, treat patients, and implement appropriate public health interventions. Innovations are being integrated in several fields of technological and engineering research to provide optimal patient care and enhance physical distancing measures. Global research platforms are also designed to encourage accelerated research, especially in potential medicinal treatment. Collaboration amongst different disciplines and countries has enabled remarkable progress in the dissemination of scientific knowledge and appropriate responses to address the consequences of this pandemic on worldwide research in STEM.
\end{abstract}

Keywords: COVID-19, STEM, global research

\section{Introduction}

With now more than 10 million confirmed cases and around half a million deaths worldwide, the Coronavirus Infectious Disease 2019 (COVID-19) pandemic has imposed a global health challenge. Healthcare workers, public health professionals and researchers are working constantly in developing treatments and solutions to mitigate virus transmission. With the increasing fatalities in counties around the world, there is an urgent need for the global academic research community to respond to this public health emergency. Addressing a complex crisis like COVID-19 requires knowledge from all dimensions of academia. As a result, many researchers in science, technology, engineering, and mathematics (STEM) fields are joining forces to improve public understanding of the disease, track reported cases and develop

Copyright (C) 2021. The Author(s). This is an open access preprint (not peer-reviewed) article under Creative Commons AttributionNonCommercial 4.0 International license, which permits any non-commercial use, distribution, adaptation, and reproduction in any medium, as long as the original work is properly cited. However, caution and responsibility are required when reusing as the articles on preprint server are not peer-reviewed. Readers are advised to click on URL/doi link for the possible availability of an updated or peer-reviewed version.

\section{How to Cite:}

Hoang and De, "Effects of COVID-19 on Global Research in STEM". AIJR Preprints, 331, Version 1, 2021. 
containment and treatment solutions. Computational scientists, artificial intelligence experts, engineers and mathematicians are among the many individuals that can contribute to pandemic efforts. As many nonCOVID-19 laboratories studies are coming to a halt, more opportunities in COVID-19 research are unfolding. This study will cover the impact of COVID-19 on research in STEM.

\section{Impact of COVID-19 on Global Institutional and Industrial Research in STEM}

Since the onset of the pandemic, research institutions have restricted several non-COVID-19 related laboratory studies. Onsite research has been reserved for essential projects and strict social distancing policies have been introduced. Essential onsite research has also limited the number of lab staff, permitting one laboratory personnel at a time (Omary et al., 2020). Rutgers University in New Jersey, US is one of the many major research institutions that has called all non-critical research to be carried out remotely while encouraging clinical COVID-19 research (Omary et al., 2020). The university's Cell and DNA repository organized high-throughput testing services for the virus, analyzing around 10,000 samples daily (Omary et al., 2020). Similarly, immunology laboratories have halted non-COVID-19 research to study the immunopathology of SARS-CoV-2 (Vabret et al., 2020). As for several cancer research projects in hospitals, COVID-19 disrupted in-person appointments and study visits, drug accountability audits, outcome assessments and research staff training (Saberi, 2020; Saini et al., 2020). Many of the research staff and resources have been relocated to COVID-19 cases instead. Remote research studies are still conducted through virtual modes, decreasing the time and cost of these projects while increasing the ease of participation. Online advertisements are used for recruitment, assessments have occurred through online platforms, and interventions are carried out through mobile reminders (Saberi, 2020). These remote methodologies have led to increase speeds in publications and reduced bias in assessments due to the removal of face-to-face communication (Saberi, 2020). With the pandemic being the new focus of scientific investigation, there is a substantial volume of COVID-19 literature published, 30\% of which has originated from China and 14\% from the United States (Haghani et al., 2020). Many different institutions, industries and counties around the world offer diverse competencies and resources to address the pandemic, encouraging global research collaboration.

\section{Impact of COVID-19 on Global Science Research}

The scientific community has made tremendous progress when responding to COVID-19. Robust research on SARS-CoV-2 and its impact on humanity is generated at an astonishing rate. Many of these research areas include characteristic of SARS-CoV-2, potential medical treatments, environmental impacts of the pandemic and the behavioral science behind physical distancing. Due to the multitude of research topics in the field of science, the impact of COVID-19 on biomedical, environmental, social, and behavioral science research shall be highlighted here.

Research on the structural characteristics and bioinformatics of SARS-CoV-2 has enabled scientific communities to understand the virus' transmission, trace the outbreak, and determine necessary epidemiologic controls. Within one month of the incident case, Chinese scientists isolated the virus and sequenced the viral genome ( $\mathrm{Yu}$ et al., 2020). On January 12, 2020, the full-length genome sequence of SARS-CoV-2 was shared with the World Health Organization. Researchers were able to determine the sequence homologies with other viruses, including a 79.6\% shared sequence identify with SARS-CoV, 50\% identity with MERS-CoV, and 96\% identity with bat corona virus (Y. Zhang et al., 2020). This enabled further comprehension of possible hosts and the initial emergence of the virus. Since then, many 
independent investigative groups worldwide have been able to isolate the virus and share the sequences publicly on the Global Initiative on Sharing All Influenza Data (GSAID) database. On January 24, the first clinical study was conducted from the Jun-yin-tan Hospital in Wuhan on 41 confirmed COVID-19 patients, $66 \%$ of which had direct exposure to the Huanan seafood market (Tang et al., 2020). Huang et al. determined the epidemiological, laboratory, clinical and radiological characteristics of the patients. They also reported the clinical outcomes of using a combination of lopinavir and ritonavir treatments (C. Huang et al., 2020). Further studies observed radiological characteristics of COVID-19 chest CT scans and determined the common symptoms of the disease (Tang et al., 2020). The first autopsy performed on a Chinese COVID-19 victim allowed researchers to study the organs affected during the disease (Tang et al., 2020). All these laboratory and clinical discoveries have aided with COVID-19 diagnosis and further research into antiviral therapies and vaccines.

There are currently many companies executing clinical trials to repurpose drugs and develop a vaccine against SARS-CoV-2 (Vellingiri et al., 2020). Biotechnology organizations and medical research agencies such as the National Institutes of Health $(\mathrm{NIH})$ in the United States are carrying out randomized controlled treatments with major drugs that have the potential to treat hospitalized COVID-19 patients (Vellingiri et al., 2020). The drugs being researched include Sarilumab, Remdesivir, Methylprednisolone, and Hydroxychloroquine. Capital Medical University and China-Japan Friendship Hospital conducted clinical trials on the efficacy of Remdesivir on adults with severe cases of COVID-19 (Y. Wang et al., 2020). Unfortunately, the intravenous Remdesivir showed no clinical improvement or clearance of the virus in patients. Researchers at Emory University, University of North Carolina, and Vanderbilt University Medical Center have begun to study EIDD-2801, a new drug that showed antiviral properties against Remdesivirresistant viruses (J. Zhang et al., 2020). Clinical trials for EIDD-2801 are expected to begin soon (J. Zhang et al., 2020). On the other hand, convalescent plasma showed effectiveness in several clinical studies, enabling the FDA to grant permission for its application on patients. In addition, research on traditional medicines and medicinal plants are being considered for COVID-19 treatment. The Ministry of AYUSH, Central Council for Research in Homeopathy, in India suggested the use of several medicinal plants and herbs to address the symptoms of COVID-19 patients (Vellingiri et al., 2020). Traditional Chinese medicines with antiviral properties were also studied in various clinical trials. Qingfei paidu decoction (QPD) become the general prescription in the treatment of COVID-19 in China due to its ability to reduce inflammation and lung injury and regulate immune system function (Guo et al., 2020). The increasing rate of global COVID-19 cases has put significant emphasis on the discovery of potential therapies.

The changes to the environment after the onset of the pandemic is another area of interest in scientific research. With majority of cities and villages in affected countries in lockdown, travel has been significantly reduced. The decreased number of vehicles on the road resulted in a significant decrease in green-house gases (Chakraborty \& Maity, 2020). The closure of industries has reduced waste emissions and lowered the use of fossil fuels, allowing recovery of ecosystems. A study analyzing air quality in India showed a 52\% reduction in pollutants such as $\mathrm{PM}_{10}, \mathrm{PM}_{2.5}, \mathrm{CO}, \mathrm{NO}_{2}$, ozone, and $\mathrm{SO}_{2}$ during lockdown (Sharma et al., 2020). In China, $\mathrm{CO}_{2}$ emissions were reduced by $25 \%$, which is equivalent to 1 million tons of carbon emissions (Wang \& Su, 2020). Reports from NASA and ESA satellites have also shown significant decreases in $\mathrm{NO}_{2}$. Nevertheless, the demands to wear face masks in public led to the increase in medical waste in the environment. Ocean Asia, an environmental non-profit organization, discovered large amounts of singleuse masks along the beaches of Hong Kong (Saadat et al., 2020). Overall, the halt of several human activities during COVID-19 lockdown has created global short-term changes in the environment, an area that is being actively investigated by environmental scientists. 
The associated psychological and neuroscientific effects of COVID-19 has led to increased priorities for mental health research (Holmes et al., 2020). A public survey conducted by the UK Academy of Medical Sciences and mental health research charity, MQ: Transforming Mental Health, highlighted concerns about increased social isolation, loneliness, anxiety, and depression during the pandemic (Holmes et al., 2020). In addition, those with previous mental health issues are faced with greater difficulty in seeking support and services. As a result, research agencies in the UK are collecting data on the mental health of the general populations and COVID-19 patients to devise appropriate psychological interventions. They are also stressing the need for global research on the effect of media usage and health messaging during COVID19 (Holmes et al., 2020). In Pakistan, researchers are studying the role of electronic media in reducing mental health and boosting public morale. Many media campaigns are designed to address public mental health. These programs have recruited healthcare professionals, psychologists, and psychiatrists to console and guide citizens on how to cope with stress during uncertain times (Bilal et al., 2020). In China, mental health associations and academic societies have gone ahead and implemented mental health services through several internet platforms ( $\mathrm{Li}$ et al., 2020). Online educational videos about self-help and coping mechanisms are available to the public and mental health professionals in Wuhan have organized expert services.

\section{Impact of COVID-19 on Global Technology Research}

There are numerous technological advances arising in midst of the pandemic. Many countries around the world implemented mobile technology for contact tracing of individuals. In Taiwan, their health insurance database was integrated with the immigration and customs database to track high-risk individuals using mobile phones (C. J. Wang et al., 2020). These technological measures were soon applied in China, Macau, and Hong Kong on January 30, 2020. Similarly, South Korea created a "trace, test and treat" method where the country's information technology system (IT) was used to track suspected cases and those in close proximity to infected individuals (Park et al., 2020). In March 2020, South Korea launched the COVID-19 Epidemiological Survey Prompt Support System for more advanced tracing (Park et al., 2020). Non-medical data from credit card companies, police, restaurants, and shops were shared with public health sectors to contain the spread of disease. In the UK and the US, the Coronavirus Pandemic Epidemiological consortium (COPE), combined the efforts of scientists in epidemiology and big data research to design the COVID-19 Symptom Tracker mobile app (Drew et al., 2020). Officials were able to take the self-reported app data from infected populations and determine emerging hotspots. In Southern Wales, COVID-19 symptoms reported one week in advance would be followed by a surge of reported cases (Park et al., 2020). The opposite was true, with a decline of reported symptoms in the app leading to a decline in confirmed cases. The app's success has now led to its development in Canada, Australia, and Sweden. Larger technological companies such as Apple and Google have also collaborated in contract tracing applications using Bluetooth technologies (Fong et al., 2020). Emerging technological research has proved to offer several benefits in understanding the global dynamics of COVID-19 incidences.

The Internet of Medical Things (IoMT) combines software applications and medical devices to help make healthcare services more efficient (Chamola et al., 2020). It has been used to monitor patients remotely, track medication orders and transmit health data through wearable devices to health care professionals Many of these tools are being advanced by medical organizations and government agencies to manage the pandemic. Experts in China employed IoMT in the COVID-19 Intelligence Diagnosis and Treatment Assistant Program (nCapp) (Bai et al., 2020). Using a series of questionnaires, nCapp can identify patients as confirmed or suspected of COVID-19 as well as the severity of their cases. It can also link 
patients to physicians for online health consultation and follow ups to prevent disease transmittance. In Vancouver, hospital acquired infections have been limited by the creation of Wanda Quick Touch buttons, an IoMT device that monitors sanitation and alerts workers of any threats to public safety (Chamola et al., 2020). Shanghai Public Health Clinical Center sought to reduce the exposure of healthcare workers by employing body temperature sensors and remotely monitoring patients from nursing stations (Tsikala Vafea et al., 2020). Meanwhile, Kinsa Health is sending millions of smart thermometers to households across the US (Chamola et al., 2020). The data from these thermometers is collected by a mobile application and organized into interactive maps for government authorities to determine potential hotpots in the nation.

The pandemic has prompted the rapid expansion of artificial intelligence (AI) technologies. AI offers safe, automated solutions to medical imaging [28]. For instance, mobile CT platforms designed by visual AI technology enable contactless scanning. The technicians are able to evaluate the optimal scanning parameters remotely (Tsikala Vafea et al., 2020). More independent AI systems are being integrated into the imaging workflow to avoid unnecessary interactions between healthcare staff and COVID-19 patients (F. Shi et al., 2020). Furthermore, AI applications are being used to improve image scan qualities through similar automated determination of scan range and centering during CT imaging (F. Shi et al., 2020). AI applications can also be used in efficient imaging-based diagnosis of COVID-19. For instance, researchers at Shanghai United Imaging Intelligence are currently attempting to use radiological methods to show changes in infected regions of COVID-19 patients. Healthcare workers are then able to determine necessary procedures using automated clinical reports generated from the AI technology. Research in AI has proved to help healthcare sectors tremendously over the past few years and it has now become crucial in the response to COVID-19.

Research into autonomous technologies has also made great global progress in reducing the burden of healthcare workers during the pandemic. Robots can provide food, clean patient-care environments, and reduce contact between frontline healthcare staff and infected individuals (Madurai Elavarasan \& Pugazhendhi, 2020). Asimov Robotics in Kerala, India, developed three-wheeled robots that serve patients food and medication (Chamola et al., 2020). Xenex Disinfection Services, founded by John Hopkins epidemiologists, created autonomic "UV LightStrike Germ-Zapping robots" to decontaminate hospital environments (Chamola et al., 2020). The UV light emitted from these robots can destroy virus DNA and disinfect several rooms in one charge. The robots are also equipped with several features such as selfnavigation and computer vision to maximize cleaning (Fong et al., 2020). Similarly, UVD robot company in Denmark developed several disinfection robots, delivering them to different parts of the United States, Europe, and Asia (Chamola et al., 2020). Spanish authorities have also employed robots for testing services. The testing features created by AI algorithms can alone increase the number of COVID-19 test from 20,000 to 80,000 daily. More recently, the heavy workload experienced by medical staff led to the creation of blood sampling robots by researchers at Robert wood Johnson University Hospital and Rutgers University (Fong et al., 2020). The robots can take blood samples at a faster rate and with higher probability of success than manual sampling by nurses. Research within the field of autonomous technology is ongoing and many other applications such as service robots for body temperature testing are being designed for the pandemic.

Another challenge posed by the pandemic is the reduction and delivery of essential supplies. Research regarding Unmanned Aerial Vehicles (UAV) or "flying drones" have been conducted to distribute medical supplies, personal protective equipment, patient lab samples and testing materials in isolated areas. Marut Drones, a company created by alumni from the Indian Institute of Technology (IIT), recently launched the production of several drones for medication delivery, sanitization, and temperature analysis (Chamola et al., 2020). These drones have several navigation features and obstacle avoidance to ensure efficient deliveries. Besides the delivery of essential hospital supplies, drones in parts of China, Australia and the 
United States have begun to delivery groceries as well (Chamola et al., 2020). Drones with camera features are also being designed to ensure citizens are following government protocols, such as identifying those without a mask (Kummitha, 2020). Furthermore, the most promising research on drones enabled early detection of potentially infected COVID-19 patients. Researchers at the University of South Australia has collaborated with DraganFly, a Canadian UAV manufacturer, to design the "pandemic drone", capable of identifying respiratory disease symptoms and measuring human temperatures and heart rates (Chamola et al., 2020). The pandemic has made great use of drone technology to enforce necessary protocols, determine future disease hotspots, and minimize human interaction in delivery services.

\section{Impact of COVID-19 on Global Engineering Research}

There have been many ways in which research areas in engineering and healthcare can be combined to help with COVID-19 containment. Like most respiratory virus infections, virion-laden respiratory droplets are said to be the main route of SARS-CoV-2 transmission (Y. Shi et al., 2020). Using knowledge in the physical sciences and engineering, researchers are attempting to combat the transmission of these droplets using self-sanitizing face masks. Antiviral molecules would be released during exhalation and remain on the mask during inhalation (H. Huang et al., 2020). Since face masks provide a physical barrier to the droplets, these on-mask chemical modulation strategies are required to block and deactivate virus nanoparticles. Besides preventing spread of the virus, face masks are also being studied for COVID-19 diagnosis. Researchers at MIT and Harvard are embedding RNA and DNA virus binding sensors into the mask, freeze drying the genetic material into the fabric and detecting the virus through florescent light (Goel et al., 2020).

Fomite infection is another form of COVID-19 transmission. To limit manual decontamination of highly touched surfaces, engineers are involved in the execution of self-sanitizing, antimicrobial surfaces and the application of copper, a metal with known antiviral properties, on stainless steel surfaces (H. Huang et al., 2020). A small number of manufacturing research labs such as the Indian Institute of Technology Delhi and Cranfield University in the UK have begun to develop these manufacturing inventions (Goel et al., 2020). Researchers from Northwestern's McCormick School of Engineering and biomedical researchers in China have begun to outline ways in which engineering can be used to invent multifunctional personal protective equipment (PPE). This includes PPE suits with wireless communication, temperature controls, physiological monitors, and anti-fogging properties (H. Huang et al., 2020). Long term research in engineering innovations is pivotal to COVID-19 management.

The shortage in mechanical ventilators has also called on the efforts of engineers. In the US, ventilators are specialty products manufactured in low volume by a small number of medical suppliers [34]. The excessive number of patients in the ICU and limited ventilators led to the creation of viable medical equipment prototypes (Pearce, 2020). Open-source manufacturing has enabled knowledge about these medical equipment designs to be researched and shared freely online for local manufacturers. "Project Open Air", created by a community of engineers and health professionals in both Portugal and the United States, is an example of one of the many rapidly evolving projects for open-source alternatives to traditional medical devices (Pearce, 2020). Research on oxygen conductors, PPE, tube connectors, and hands-free door handles has also been conducted and shared on online databases (Pearce, 2020). Although many of these alternative models are not approved by the United States' FDA, these online designs have been useful in countries with less restrictions and urgent demands for life saving equipment (Armani et al., 2020). Students at research institutions have also begun to take part on open-source manufacturing. For instance, engineers from the University of Wisconsin began working with local industries to create open-source 
designs for face shields (Armani et al., 2020). Knowledge in engineering plays a vital role in delivering solutions to the urgent need for ICU resources.

\section{Impact of COVID-19 on Global Mathematics Research}

Recent research in mathematics is directed towards epidemiological models that predict the rate of COVID19 transmission. Both simple and complex mathematical models consist of systems of equations that mimic conditions in reality (Tsikala Vafea et al., 2020). Several factors such as population interaction, economic conditions, and demographics must be considered to explore plausible scenarios of the spread of disease. There are several different types of models and they are often viewed complementary to one another.

Many models are inspired by artificial intelligence machine learning, an approach using elements in statistics, mathematics, and computer science to forecast the number of infected individuals based on diverse data sources (Sidey-Gibbons \& Sidey-Gibbons, 2019). Researchers at John Hopkins University in Baltimore, US hosted projects to develop interactive, online dashboards to monitor and report COVID-19 cases (Dong et al., 2020). The dashboard includes the number of reported cases, deaths and recoveries for all countries affected by COVID-19. One study conducted in China is using a susceptible-exposed-infectedremoved (SEIR) model to predict epidemic peaks and trends in Zhejiang, Guangdong, and Hubei provinces (Yang et al., 2020). This SEIR model represents the different phases of the infectious epidemic disease and is constructed based on data from the National Health Commission of China (Yang et al., 2020). Various European countries have used The Nonlinear Autoregression Neural Network (NARNN) model, another machine learning technique that predicts the total number of COVID-19 cases over a certain time interval (Kirbas et al., 2020). The machine learning algorithm has also been applied to identify COVID-19 cases using phone surveys. Information on people's travel history and symptoms is collected to identify high-risk cases and help them implement appropriate quarantine measures (Srinivasa Rao \& Vazquez, 2020). Ultimately, the many projects involving AI frameworks have become useful to both predict areas of high infection and employ necessary policies.

Epidemiological models are being used to understand the possible contours of the epidemic and predict the maintenance of ICU resources. An age-structured compartmental model on the spread of COVID-19 was developed in Ontario, Canada to determine different outcomes of the pandemic in several scenarios: one base case with limited physical distancing and testing, the second with increased testing and restrictive isolation and cases with a combination of increased testing and moderate physical distancing (Tuite et al., 2020). Results demonstrated that an absence of isolation and the combination of testing with moderate distancing will still overwhelm the health system capacity. Though these models, researchers determined that dynamic physical distancing offers the most sustainable solution to controlling transmission while reducing societal disruptions (Tuite et al., 2020).

A similar mathematical model was constructed to determine the role of social distancing in decreasing the burden of COVID-19 in the United States. The model was inspired by the Kermack-Mckendrick theory which uses nonlinear differential equation systems to determine the distribution of infectious diseases in a closed population over time (Ngonghala et al., 2020). Based on mortality data, these models aim to provide a real-time analysis of COVID-19 in disease epicenters such as New York. Furthermore, an analysis of specific non-pharmaceutical intervention (NPI) strategies such as physical distancing, isolation, and using face masks in public is conducted to predict appropriate protocols to minimize transmission. The models showed that strict physical distancing and lock-down could reduce hospitalization of reported cases in the United States by $92 \%$ and mortality by $80 \%$ (Ngonghala et al., 2020). The study also shows that if $75 \%$ of the population wears face masks, there could be a $63 \%$ decrease in the hospitalizations of reported cases. 
Similar data results have been obtained from a stochastic mathematical model of the epidemic in India. The model shows that achieving $50 \%$ or greater quarantine compliance can lead to a $90 \%$ decline in the number of COVID-19 cases, deaths, hospitalizations, and ICU demands (Chatterjee et al., 2020). Moreover, the same model determined the long-term effects of COVID-19, showing that 55-65\% of the population in India will be infected when herd immunity is developed (Chatterjee et al., 2020). Performing these numerical stimulations proves to be extremely useful for global public health sectors to determine outbreak trajectories and the effectiveness of different NPI intervention methods.

Further research to enhance the accuracy of these mathematical models is ongoing. Resusceptibility plays a significant role in prolonging the pandemic (Ng \& Gui, 2020). As a result, recent SEIR models are redesigned to consider the possibility of a recovered patient being reinfected by COVID-19 and the associated time delays of resusceptibility. These characteristic time delays enable a better reflection on the timing of transmission across a nation. In addition, the models are incorporating demographic information about the aging population due to the higher fatality rate amongst these vulnerable groups $(\mathrm{Ng} \&$ Gui, 2020). Cases studies based on real-world data from South Korea and Northern Ireland have proven that these modified models enable more accurate predictions. As research regarding these models continue to expand, they will provide public health officials with valuable data on periods of possible overwhelming of healthcare capacity.

\section{Discussion}

COVID-19 has had a profound impact on global STEM research. The cancellation of in-person appointments inhibited several studies, causing delays in industry and hospital based- research. The same case is seen in academia, where research institutions have restricted non-COVID-19 related projects and limited the number of critical laboratory staff. COVID-19 research funding has also been prioritized, leading to potential discontinuation of non-COVID-19 research studies. Most importantly, researchers in STEM are now directing their efforts towards the pandemic. While virologists may seem to play the most important role in understanding the virus, it is the additional help of physical scientists, psychologists, engineers, mathematicians, and technology experts that has enabled a comprehensive look into COVID19 management. The worldwide spread of the disease increased demands to gauge the pathogenic and clinical characteristic of COVID-19 infection. In the field of science, medical communities have focused on the development of medication and therapies for COVID-19 patients. Several antiviral drugs are being tested in laboratories throughout the world and traditional medicines are being considered in parts of China and India. Global collaboration in this field has been essential, as demonstrated by the shared online genomic database used to decipher the origins of SARS-CoV-2. By conducting clinical trials and creating global research platforms, scientists have been able to make faster advancements in vaccine development.

Emerging technologies has relieved the demands of healthcare workers while enforcing physical distancing measures. Countries around the world are using technology in hospital services, medical equipment delivery and diagnostic tests. As technology in one country succeeds, this knowledge is passed on to the creation of similar applications in another country. This is particularly true in contact-tracing technologies where public health officials can predict COVID-19 hotspots. Research in mathematics has played a similar role, with epidemiological models providing accurate information on COVID-19 transmission rates. Meanwhile, research in engineering has proposed several solutions to the shortage of medical equipment and advancement of current PPE. Although the science, technology, engineering, and mathematic fields contribute in different ways to address COVID-19, all the research has been essential in mitigating virus transmission and treating infected individuals. Many of these studies will also prepare 
experts in unforeseen outbreaks. Overall, the collaboration amongst different disciplines and countries has enabled rapid and substantial global output in COVID-19 research.

COVID-19 adversely affected practically all sectors and levels of education worldwide including STEM and healthcare, in addition to research in those disciplines (Autore \& De, 2021; Autore et al., 2020; Autore et al., 2021; De, 2020b; Hallett et al., 2021; Hallett \& De, 2020; Hoang et al., 2021). Improving research in STEM largely depends on greater efficiency at meeting specific requirements of STEM education in schools and colleges. College STEM education stakeholders, viz. students, faculty, and academic institutional administrators have already been facing multifarious challenges (Arguello et al., 2020; De \& Arguello, 2020). On top of that, COVID-19 imposed the need to complement or supplement inperson STEM classes with virtual instruction. Educators and administrative personnel may address this requirement by considering pertinent reports of increasing student engagement and learning in science through free/low-cost mobile apps in middle/high school or college (De \& Nethi, 2019; De \& Nethi, 2020; Nethi \& De, 2019; Nethi \& De, 2020), developing and implementing virtual classrooms (De \& Cavanaugh, 2020), organizing and contributing to digital leadership forums (De, 2020a), adopting novel ways of assessment such as peer-video-blogs (Luyegu \& De, 2020), and may need to revise modern strategies of assessing science research-based courses like one designed recently (Kapil, De, et al., 2021; Kapil, Pathak, et al., 2021; Kim, Haughton, et al., 2020; Kim, Muchintala, et al., 2020; Pathak et al., 2021). In this context, it is STEM research which could be leveraged to mitigate the viral contagion by empowering communities with health literacy (Paakkari \& Okan, 2020) and awareness about food safety as well as about the role scientific research can play in meeting the heightened demands of food production and nutrition owing to the pandemic, understandable from multiple reports (De, 2010; De, 2019, 2020c; De \& Bandyopadhyay, 2008).

\section{Conclusions}

This current study evaluates the impact of COVID-19 on research in STEM. It was inferred that research in all disciplines is essential to the global fight against COVID-19. In the field of science, institutions and industries are focused on developing vaccines and anti-viral treatments for patients. Nevertheless, other lenses of the pandemic beyond therapies are considered as well, with psychologists trying to comprehend the psychosocial impacts of isolation and environmentalists determining the impacts of lockdown on the climate crisis. The pandemic has also pushed the development of health and AI technologies, relieving burden from healthcare sectors, and encouraging physical distancing. A coalition of research institutions and engineers have contributed to health services through innovative ideas to personal protective equipment and medical technologies alternatives. Finally, different countries have implemented all types of mathematical models to unravel the transmission-rates and inform decision-makers about necessary interventions for ensuring public safety. Through all these research projects, corporation and coordination amongst different countries has enabled faster solutions to the array of social, economic, environmental, and clinical problems that arise from the pandemic. It is also noted that the rapid expansion of COVID-19 research suspended several non-COVID-19 studies. As a result, remote research is being conducted through online platforms. Ultimately, this literature review shows that global health emergencies like the COVID-19 pandemic requires attention and expertise from diverse disciplines as well as international collaboration. Each research project examined in this work has devised actionable solutions to COVID-19 in its own way and can be applied in future outbreaks. It should be noted that a limited number of research projects were mentioned in the study due to the wide scope of investigations occurring during the 
pandemic. It is also recommended that future studies should focus on further, in-depth analysis of the impact of COVID-19 on research associated with each specific discipline in STEM.

\section{Declarations}

\subsection{Study Limitations and Future Recommendations}

Insights into the major research projects in the STEM field were mentioned in the study. Thus, there are several other projects that were not covered. Additionally, research in Africa and parts of Europe were not as prevalent as studies conducted in the United States, China, and the United Kingdom. It is recommended that future studies should investigate the effects of COVID-19 on subject-specific research activities in STEM.

\subsection{Competing Interests}

The authors declare no competing interests involved.

\section{References}

Arguello, G., De, S., \& Orta, S. (2020). An Analysis of STEM Education at the College Level: Stakeholders' Perspectives [Conference Presentation]. Biology Faculty Proceedings, Presentations, Speeches, Lectures, Article 426. https://nsuworks.nova.edu/cnso_bio_facpres/426

Armani, A. M., Hurt, D. E., Hwang, D., McCarthy, M. C., \& Scholtz, A. (2020). Low-tech solutions for the COVID-19 supply chain crisis. Nat Rev Mater, 1-4. https://doi.org/10.1038/s41578-020-0205-1

Autore, S., \& De, S. (2021). Effects of COVID-19 on Global Healthcare Research and Management. AIJR Preprints, Article 314. https://doi.org/https://doi.org/10.21467/preprints.314

Autore, S., Hallet, J., Hoang, M., \& De, S. (2020). Impact of COVID-19 on Global Education and Research in Healthcare and STEM [Presentation]. https://nsuworks.nova.edu/trick/2020/events/8/ (Trick to the Treat of Internships and Research, Nova Southeastern University)

Autore, S., Hallett, J., Hoang, M., \& De, S. (2021). Navigating COVID-19-based Challenges to Global Education, Research, and Management in Healthcare and STEM [Conference Presentation]. Biology Faculty Proceedings, Presentations, Speeches, Lectures, Article 430. https://nsuworks.nova.edu/cnso_bio_facpres/430

Bai, L., Yang, D., Wang, X., Tong, L., Zhu, X., Zhong, N., Bai, C., Powell, C. A., Chen, R., \& Zhou, J. (2020). Chinese experts' consensus on the Internet of Things-aided diagnosis and treatment of coronavirus $\begin{array}{llllll}\text { disease } & 2019 & \text { (COVID-19). } & \text { Clinical } & \text { eHealth, } & 3,\end{array}$ https://doi.org/https://doi.org/10.1016/j.ceh.2020.03.001

Bilal, Latif, F., Bashir, M. F., Komal, B., \& Tan, D. (2020). Role of electronic media in mitigating the psychological impacts of novel coronavirus (COVID-19). Psychiatry Res, 289, 113041. https://doi.org/10.1016/j.psychres.2020.113041

Chakraborty, I., \& Maity, P. (2020). COVID-19 outbreak: Migration, effects on society, global environment and prevention. Sci Total Environ, 728, 138882. https://doi.org/10.1016/j.scitotenv.2020.138882

Chamola, V., Hassija, V., Gupta, V., \& Guizani, M. (2020). A Comprehensive Review of the COVID-19 Pandemic and the Role of IoT, Drones, AI, Blockchain, and 5G in Managing its Impact. IEEE Access, 8, 90225-90265. https://doi.org/10.1109/ACCESS.2020.2992341

Chatterjee, K., Chatterjee, K., Kumar, A., \& Shankar, S. (2020). Healthcare impact of COVID-19 epidemic in India: A stochastic mathematical model. Med $J$ Armed Forces India, 76(2), 147-155. https://doi.org/10.1016/j.mjafi.2020.03.022 
Hoang and De, AIJR Preprints, 331, version 1, 2021

De, S. (2010). Food safety: Steps of rising concern. Everyman's Science, XLV(4), 219-222. https://nsuworks.nova.edu/cnso_bio_facarticles/941

De, S. (2019). Identification and Cloning of Putative Serine Protease Inhibitor (Serpin) Genes in Rice (Oryza sativa) and a Preliminary Approach to Generate RNAi using the Cloned Sequences [Preprint]. 1-33, Article 978. https://nsuworks.nova.edu/cnso_bio_facarticles/978

De, S. (2020a). Anatomy and Physiology Breakout Session/Focus Group, Pearson's Digital Leadership Forum, Orlando, FL, USA [Panel Discussion]. Biology Faculty Proceedings, Presentations, Speeches, Lectures, Article 420. https://nsuworks.nova.edu/cnso_bio_facpres/420

De, S. (2020b). Impacts of the COVID-19 Pandemic on Global Education [Book Chapter]. 84-94. https://doi.org/10.26524/royal.37.6 (Royal Book Publishing)

De, S. (2020c). Strategies of Plant Biotechnology to Meet the Increasing Demand of Food and Nutrition in India. International Annals of Science, 10(1), 7-15. https://doi.org/https://doi.org/10.21467/ias.10.1.7-15

De, S., \& Arguello, G. (2020). STEM Education in College: An Analysis of Stakeholders' Recent Challenges and Potential Solutions. FDLA Journal, 5, Article 9. https://nsuworks.nova.edu/fdla-journal/vol5/iss1/9

De, S., \& Bandyopadhyay, S. (2008). Molecular Taxonomy: An Approach Based on Molecular Markers. Science and Culture, 74, 397-496. https://nsuworks.nova.edu/cnso_bio_facarticles/940/

De, S., \& Cavanaugh, G. (2020). Navigating Healthcare Science Student Learning and Engagement Through Implementation of a Virtual Classroom [Conference Presentation]. Biology Faculty Proceedings, Presentations, Speeches, Lectures, Article 419. https://nsuworks.nova.edu/cnso_bio_facpres/419

De, S., \& Nethi, V. (2019). The potential of socio-biologically relevant mobile apps to attract girls to STEM [Conference Presentation]. Biology Faculty Proceedings, Presentations, Speeches, Lectures, Article 334. https://nsuworks.nova.edu/cnso_bio_facpres/334

De, S., \& Nethi, V. (2020). Impact of Science Mobile Applications on Interest and Learning Among Undergraduate Science Students. Quarterly Review of Distance Education, 21(4), 37-50. https://nsuworks.nova.edu/cnso_bio_facarticles/1060

Dong, E., Du, H., \& Gardner, L. (2020). An interactive web-based dashboard to track COVID-19 in real time. The Lancet Infectious Diseases, 20(5), 533-534. https://doi.org/https://doi.org/10.1016/S14733099(20)30120-1

Drew, D. A., Nguyen, L. H., Steves, C. J., Menni, C., Freydin, M., Varsavsky, T., Sudre, C. H., Cardoso, M. J., Ourselin, S., Wolf, J., Spector, T. D., Chan, A. T., \& Consortium, C. (2020). Rapid implementation of mobile technology for real-time epidemiology of COVID-19. Science, 368(6497), 1362-1367. https://doi.org/10.1126/science.abc0473

Fong, S. J., Dey, N., \& Chaki, J. (2020). AI-enabled technologies that fight the coronavirus outbreak. In Artificial Intelligence for Coronavirus Outbreak (pp. 23-45). Springer. https://doi.org/10.1007/978-981-15-59365_2

Goel, S., Hawi, S., Goel, G., Thakur, V. K., Agrawal, A., Hoskins, C., Pearce, O., Hussain, T., Upadhyaya, H. M., Cross, G., \& Barber, A. H. (2020). Resilient and agile engineering solutions to address societal challenges such as coronavirus pandemic. Mater Today Chem, 17, 100300. https://doi.org/10.1016/j.mtchem.2020.100300

Guo, G., Ye, L., Pan, K., Chen, Y., Xing, D., Yan, K., Chen, Z., Ding, N., Li, W., Huang, H., Zhang, L., Li, X., \& Xue, X. (2020). New Insights of Emerging SARS-CoV-2: Epidemiology, Etiology, Clinical Features, Clinical Treatment, and Prevention. Front Cell Dev Biol, 8, 410. https://doi.org/10.3389/fcell.2020.00410

Haghani, M., Bliemer, M. C. J., Goerlandt, F., \& Li, J. (2020). The scientific literature on Coronaviruses, COVID19 and its associated safety-related research dimensions: A scientometric analysis and scoping review. Saf Sci, 129, 104806. https://doi.org/10.1016/j.ssci.2020.104806

Hallett, J., Autore, S., Hoang, M., \& De, S. (2021). COVID-19-based Challenges and Countermeasures in Education, Research, and Management in Healthcare and STEM [Conference Presentation]. Biology 


Faculty Proceedings, Presentations, Speeches, Lectures, Article 431.
https://nsuworks.nova.edu/cnso_bio_facpres/431

Hallett, J., \& De, S. (2020). Effects of COVID-19 on Education in Healthcare and STEM. AIJR Preprints, 275(1). https://preprints.aijr.org/index.php/ap/preprint/view/275

Hoang, M., Hallett, J., Autore, S., \& De, S. (2021). Education, research, and management in STEM and healthcare: global impacts of COVID-19 [Conference Presentation]. Biology Faculty Proceedings, Presentations, Speeches, Lectures, Article 432. https://nsuworks.nova.edu/cnso_bio_facpres/432

Holmes, E. A., O'Connor, R. C., Perry, V. H., Tracey, I., Wessely, S., Arseneault, L., Ballard, C., Christensen, H., Silver, R. C., \& Everall, I. J. T. L. P. (2020). Multidisciplinary research priorities for the COVID-19 pandemic: a call for action for mental health science.

Huang, C., Wang, Y., Li, X., Ren, L., Zhao, J., Hu, Y., Zhang, L., Fan, G., Xu, J., \& Gu, X. (2020). Clinical features of patients infected with 2019 novel coronavirus in Wuhan, China. The lancet, 395(10223), 497506. https://doi.org/https://doi.org/10.1016/S0140-6736(20)30183-5

Huang, H., Fan, C., Li, M., Nie, H. L., Wang, F. B., Wang, H., Wang, R., Xia, J., Zheng, X., Zuo, X., \& Huang, J. (2020). COVID-19: A Call for Physical Scientists and Engineers. ACS Nano, 14(4), 3747-3754. https://doi.org/10.1021/acsnano.0c02618

Kapil, A., De, S., \& Sikora, A. (2021). Analysis of Student Learning Gains in a Biochemistry CURE course during the mandatory COVID-19 shift to online learning [Conference Presentation]. Biology Faculty Proceedings, Presentations, Speeches, $\quad$ Lectures, Article 434. https://nsuworks.nova.edu/cnso_bio_facpres/434

Kapil, A., Pathak, N., Sikora, A., \& De, S. (2021). Assessment of Student Mastery of Anticipated Learning Outcomes During a BlendFlex STEM CURE Using a Combination of Self-reported and Empirical Analysis [Conference Presentation]. Biology Faculty Proceedings, Presentations, Speeches, Lectures, Article 429. https://nsuworks.nova.edu/cnso_bio_facpres/429

Kim, B., Haughton, O., Muchintala, R., De, S., \& Sikora, A. (2020). Design of research-based assessment strategies for a biochemistry CURE using published learning outcomes [Conference Presentation]. Biology Faculty Proceedings, Presentations, Speeches, Lectures, Article 425. https://nsuworks.nova.edu/cnso_bio_facpres/425

Kim, B., Muchintala, R., Haughton, O., De, S., \& Sikora, A. (2020). Novel Assessment Strategies for Biochemistry Courses Using the Research-Based Biochemistry Authentic Student Inquiry Lab (BASIL) Model [Conference Presentation]. Biology Faculty Proceedings, Presentations, Speeches, Lectures, Article 423. https://nsuworks.nova.edu/cnso_bio_facpres/423

Kirbas, I., Sozen, A., Tuncer, A. D., \& Kazancioglu, F. S. (2020). Comparative analysis and forecasting of COVID-19 cases in various European countries with ARIMA, NARNN and LSTM approaches. Chaos Solitons Fractals, 138, 110015. https://doi.org/10.1016/j.chaos.2020.110015

Kummitha, R. K. R. (2020). Smart technologies for fighting pandemics: The techno- and human- driven approaches in controlling the virus transmission. Gov Inf Q, 37(3), 101481. https://doi.org/10.1016/j.giq.2020.101481

Li, W., Yang, Y., Liu, Z. H., Zhao, Y. J., Zhang, Q., Zhang, L., Cheung, T., \& Xiang, Y. T. (2020). Progression of Mental Health Services during the COVID-19 Outbreak in China. Int J Biol Sci, 16(10), 1732-1738. https://doi.org/10.7150/ijbs.45120

Luyegu, E., \& De, S. (2020). Peer-Video-Blog Assessment: An Innovative Approach to Assessment [Conference Presentation]. Biology Faculty Proceedings, Presentations, Speeches, Lectures, Article 428. https://nsuworks.nova.edu/cnso_bio_facpres/428/

Madurai Elavarasan, R., \& Pugazhendhi, R. (2020). Restructured society and environment: A review on potential technological strategies to control the COVID-19 pandemic. Sci Total Environ, 725, 138858. https://doi.org/10.1016/j.scitotenv.2020.138858 
Nethi, V., \& De, S. (2019). The Potential of Socio-biologically Relevant Mobile Applications to Attract Girls to STEM. FDLA Journal, 4(1), Article 4. https://nsuworks.nova.edu/fdla-journal/vol4/iss1/4

Nethi, V., \& De, S. (2020). Use of Science Mobile Apps among Undergraduate Science Students and Its Impact on Their Interest and Learning [Conference Presentation]. Biology Faculty Proceedings, Presentations, Speeches, Lectures, Article 427. https://nsuworks.nova.edu/cnso_bio_facpres/427/

Ng, K. Y., \& Gui, M. M. (2020). COVID-19: Development of a robust mathematical model and simulation package with consideration for ageing population and time delay for control action and resusceptibility. Physica D, 411, 132599. https://doi.org/10.1016/j.physd.2020.132599

Ngonghala, C. N., Iboi, E., Eikenberry, S., Scotch, M., MacIntyre, C. R., Bonds, M. H., \& Gumel, A. B. (2020). Mathematical assessment of the impact of non-pharmaceutical interventions on curtailing the 2019 novel Coronavirus. Math Biosci, 325, 108364. https://doi.org/10.1016/j.mbs.2020.108364

Omary, M. B., Eswaraka, J., Kimball, S. D., Moghe, P. V., Panettieri, R. A., Jr., \& Scotto, K. W. (2020). The COVID-19 pandemic and research shutdown: staying safe and productive. J Clin Invest, 130(6), 27452748. https://doi.org/10.1172/JCI138646

Paakkari, L., \& Okan, O. (2020). COVID-19: health literacy is an underestimated problem. The Lancet Public Health, 5(5), e249-e250. https://doi.org/https://doi.org/10.1016/S2468-2667(20)30086-4

Park, S., Choi, G. J., \& Ko, H. (2020). Information Technology-Based Tracing Strategy in Response to COVID19 in South Korea-Privacy Controversies. JAMA, 323(21), 2129-2130. https://doi.org/10.1001/jama.2020.6602

Pathak, N., Tariq, M., De, S., \& Sikora, A. (2021). Analysis of student mastery of anticipated learning outcomes during a BlendFlex STEM CURE using a combination of self-reported and empirical analysis [Conference Presentation]. Biology Faculty Proceedings, Presentations, Speeches, Lectures, Article 433. https://nsuworks.nova.edu/cnso_bio_facpres/433

Pearce, J. M. (2020). A review of open source ventilators for COVID-19 and future pandemics. F1000Res, 9, 218. https://doi.org/10.12688/f1000research.22942.2

Saadat, S., Rawtani, D., \& Hussain, C. M. (2020). Environmental perspective of COVID-19. Sci Total Environ, 728, 138870. https://doi.org/10.1016/j.scitotenv.2020.138870

Saberi, P. (2020). Research in the Time of Coronavirus: Continuing Ongoing Studies in the Midst of the COVID19 Pandemic. AIDS Behav, 24(8), 2232-2235. https://doi.org/10.1007/s10461-020-02868-4

Saini, K. S., de las Heras, B., de Castro, J., Venkitaraman, R., Poelman, M., Srinivasan, G., Saini, M. L., Verma, S., Leone, M., \& Aftimos, P. (2020). Effect of the COVID-19 pandemic on cancer treatment and research. The Lancet Haematology, 7(6), e432. https://doi.org/https://doi.org/10.1016/S2352-3026(20)30123-X

Sharma, S., Zhang, M., Anshika, Gao, J., Zhang, H., \& Kota, S. H. (2020). Effect of restricted emissions during COVID-19 on air quality in India. Sci Total Environ, 728, 138878. https://doi.org/10.1016/j.scitotenv.2020.138878

Shi, F., Wang, J., Shi, J., Wu, Z., Wang, Q., Tang, Z., He, K., Shi, Y., \& Shen, D. (2020). Review of Artificial Intelligence Techniques in Imaging Data Acquisition, Segmentation and Diagnosis for COVID-19. IEEE Rev Biomed Eng, PP. https://doi.org/10.1109/RBME.2020.2987975

Shi, Y., Wang, G., Cai, X. P., Deng, J. W., Zheng, L., Zhu, H. H., Zheng, M., Yang, B., \& Chen, Z. (2020). An overview of COVID-19. J Zhejiang Univ Sci B, 21(5), 343-360. https://doi.org/10.1631/jzus.B2000083

Sidey-Gibbons, J. A. M., \& Sidey-Gibbons, C. J. (2019). Machine learning in medicine: a practical introduction. BMC Med Res Methodol, 19(1), 64. https://doi.org/10.1186/s12874-019-0681-4

Srinivasa Rao, A. S. R., \& Vazquez, J. A. (2020). Identification of COVID-19 can be quicker through artificial intelligence framework using a mobile phone-based survey when cities and towns are under quarantine. Infect Control Hosp Epidemiol, 41(7), 826-830. https://doi.org/10.1017/ice.2020.61

Tang, D., Comish, P., \& Kang, R. (2020). The hallmarks of COVID-19 disease. PLoS Pathog, 16(5), e1008536. https://doi.org/10.1371/journal.ppat.1008536 
Effects of COVID-19 on Global Research in STEM

Tsikala Vafea, M., Atalla, E., Georgakas, J., Shehadeh, F., Mylona, E. K., Kalligeros, M., \& Mylonakis, E. (2020). Emerging Technologies for Use in the Study, Diagnosis, and Treatment of Patients with COVID-19. Cell Mol Bioeng, 1-9. https://doi.org/10.1007/s12195-020-00629-w

Tuite, A. R., Fisman, D. N., \& Greer, A. L. (2020). Mathematical modelling of COVID-19 transmission and mitigation strategies in the population of Ontario, Canada. CMAJ, 192(19), E497-E505. https://doi.org/10.1503/cmaj.200476

Vabret, N., Samstein, R., Fernandez, N., Merad, M., Sinai Immunology Review, P., Trainees, \& Faculty. (2020). Advancing scientific knowledge in times of pandemics. Nat Rev Immunol, 20(6), 338. https://doi.org/10.1038/s41577-020-0319-0

Vellingiri, B., Jayaramayya, K., Iyer, M., Narayanasamy, A., Govindasamy, V., Giridharan, B., Ganesan, S., Venugopal, A., Venkatesan, D., Ganesan, H., Rajagopalan, K., Rahman, P., Cho, S. G., Kumar, N. S., \& Subramaniam, M. D. (2020). COVID-19: A promising cure for the global panic. Sci Total Environ, 725 , 138277. https://doi.org/10.1016/j.scitotenv.2020.138277

Wang, C. J., Ng, C. Y., \& Brook, R. H. (2020). Response to COVID-19 in Taiwan: Big Data Analytics, New Technology, and Proactive Testing. JAMA, 323(14), 1341-1342. https://doi.org/10.1001/jama.2020.3151

Wang, Q., \& Su, M. (2020). A preliminary assessment of the impact of COVID-19 on environment - A case study of China. Sci Total Environ, 728, 138915. https://doi.org/10.1016/j.scitotenv.2020.138915

Wang, Y., Zhang, D., Du, G., Du, R., Zhao, J., Jin, Y., Fu, S., Gao, L., Cheng, Z., \& Lu, Q. (2020). Remdesivir in adults with severe COVID-19: a randomised, double-blind, placebo-controlled, multicentre trial. The lancet. https://doi.org/https://doi.org/10.1016/S0140-6736(20)31022-9

Yang, Z., Zeng, Z., Wang, K., Wong, S. S., Liang, W., Zanin, M., Liu, P., Cao, X., Gao, Z., Mai, Z., Liang, J., Liu, X., Li, S., Li, Y., Ye, F., Guan, W., Yang, Y., Li, F., Luo, S., Xie, Y., Liu, B., Wang, Z., Zhang, S., Wang, Y., Zhong, N., \& He, J. (2020). Modified SEIR and AI prediction of the epidemics trend of COVID-19 in China under public health interventions. $J$ Thorac Dis, 12(3), 165-174. https://doi.org/10.21037/jtd.2020.02.64

Yu, J., Chai, P., Ge, S., \& Fan, X. (2020). Recent Understandings Toward Coronavirus Disease 2019 (COVID19): From Bench to Bedside. Front Cell Dev Biol, 8, 476. https://doi.org/10.3389/fcell.2020.00476

Zhang, J., Xie, B., \& Hashimoto, K. (2020). Current status of potential therapeutic candidates for the COVID-19 crisis. Brain Behav Immun, 87, 59-73. https://doi.org/10.1016/j.bbi.2020.04.046

Zhang, Y., Xu, J., Li, H., \& Cao, B. (2020). A Novel Coronavirus (COVID-19) Outbreak: A Call for Action. Chest, 157(4), e99-e101. https://doi.org/10.1016/j.chest.2020.02.014 